\title{
Lean blow-off scaling of turbulent premixed bluff-body flames of vapourised liquid fuels
}

\author{
Rohit S. Pathania*, Aaron W. Skiba ${ }^{\dagger}$, Jenni A. M. Sidey-Gibbons ${ }^{\ddagger}$, Epaminondas Mastorakos ${ }^{\S \mathbb{I}}$ \\ Department of Engineering, University of Cambridge, Cambridge, CB2 1PZ, UK
}

The lean blow-off (LBO) limits and structure of turbulent premixed flames were investigated with vapourised liquid fuels stabilized by a bluff-body burner. Ethanol, heptane, and two kerosenes were used. In order to facilitate comparisons to gaseous-fueled flames, results were also obtained from methane flames. The measured LBO limits indicate that, for this burner, the ethanol and heptane flames are more resilient to blow-off than the kerosene fuels. Furthermore, a correlation based on a Damköhler number (Da), which is proportional to the laminar flame speed, does not lead to the successful collapse of the different fuels, indicating that the Da correlations based on laminar flame speed is not applicable. Average $\mathrm{OH}^{*}$ chemiluminescence images of the ethanol and heptane flames are qualitatively similar to that from methane: the flame brushes of both exhibit an M-shape when close to blow-off. In contrast, the distribution of $\mathrm{OH}^{*}$ signal in the kerosene flames is primarily concentrated in regions further downstream of the bluff body. Ultimately, the results of this effort highlight the influence fuel-type has on the LBO of bluff-body stabilized flames. Moreover, this work indicates the LBO behavior of flames produced with complex hydrocarbon fuels cannot be fully understood via high-temperature chemistry concepts such as the laminar flame speed.

Turbulent premixed combustion, blow-off scaling, Vapourise kerosene

\section{Introduction}

$\mathrm{S}$ TABILISATION of lean premixed flames is of considerable importance for next-generation gas turbine combustors premixed or non-premixed flames, which facilitates a substantial reduction in total NOx production [3]. However, because premixed flames are prone to blow-off, this renders the design and development of practical devices that can robustly stabilise premixed flames over a broad range of conditions challenging [4].

Numerous experiments have been performed to understand lean blow-off (LBO), which is a long-standing issue

*Ph.D, Dept. of Engineering, Member AIAA.

${ }^{\dagger}$ Research Associate, Dept. of Engineering, Member AIAA.

Lecturer, Dept. of Engineering, Member AIAA.

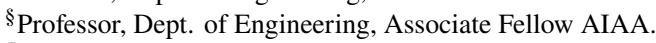

"IA version of this paper was presented at the AIAA SciTech 2019 Forum, 7 - 11 Jan., San Diego, California, as paper AIAA-2019-2238 
within the premixed combustion community [5,6]. Based on these experiments, various empirical formulations have been proposed, correlating blow-off limits as a function of bulk flow velocity, equivalence ratio, fuel type, blockage ratio, bluff-body shape, pressure, and temperature [7]. These empirical correlations attributed blow-off to conditions wherein the chemical time scales exceeded that associated with the turbulent flow field. Radhakrishnan et al. [8] proposed a simple blow-off velocity correlation based on a conceptual model for high Reynolds number turbulent premixed flame propagation. They defined two characteristic timescales: 1) a chemical time, defined as the time the flame took to traverse across the Taylor microscale $(\lambda)$ and 2) a fluid dynamic time, specified as the characteristic eddy turnover time. They further assumed the chemical timescale depends on the laminar flame speed and that the eddy timescale is based on the size of the recirculation zone (RZ) and the bulk velocity. These definitions lead to the following correlation:

$$
\frac{1}{D a}=\left[\left(\frac{C_{1}}{C_{2}} \frac{15}{A}\right)\left(\frac{U_{b}}{d} \frac{v}{S_{L}^{2}}\right)\right]^{1 / 2}
$$

In Eq. 1. $C_{1}, C_{2}$, and $A$ are constants, $v$ is the kinematic viscosity, $U_{b}$ is the bulk air velocity, $d$ is the diameter of the flame holder, $S_{L}$ is the laminar flame speed, and $D a$ is the Damköhler number. More recent efforts by Kariuki et al. [9] have provided support for the ability of this correlation to predict the LBO of methane flames. They validated this correlation over several bluff body diameters and a range of $U_{b}$. They found that Eq. 1 1 collapses LBO data from methane flames, indicating that blow-off is strongly linked to the laminar flame speed. Shanbhogue et al. [6] showed that the scaling based on unburnt gaseous velocities rather than burnt gaseous velocities provides a better collapse of the data than the scaling in Ref. [8]. Moreover, their comprehensive analysis showed that the simple correlation in Eq. 1] can be implemented to achieve consistent results across a wide range of conditions and geometries, hence demonstrating that for simple gaseous fuels, a blow-off correlation can be obtained without the need for empirical fits or adjustable constants.

The flame shape and LBO phenomena of turbulent premixed bluff-body flames were previously investigated with methane, ethylene, and propane in Refs. [9-11] and those therein. Kariuki et al. [9] studied the flame shape using $\mathrm{OH}^{*}$ chemiluminescence and showed that the flame brush is primarily located in the shear layer under stable burning conditions. In contrast, when close to blow-off, the flame becomes shorter with the downstream part of the flame brush closing across the recirculation zone. Under such conditions, the flames exhibit an M-shape, with a significant amount of reaction being observed within the RZ. Such change in flame shape was also observed in Refs. [11, 12] as those flames approached LBO. During LBO, Pathania et al. [13] found kerosene-fueled flames to also recede to the RZ as they approached LBO. They found a clear difference in flame structure between methane and Jet-A flames. Their results manifested that $\mathrm{LBO}$ knowledge based on a $\mathrm{CH}_{4}$-air mixture cannot be fully transposed to complex hydrocarbon fuels.

The ability of Eq. 1 to predict blow-off in a swirl stabilized premixed, non-premixed, and spray flames was reported in Ref. [14]. They found that all three flames extinguished at the same critical Da, providing support for using Eq.11 to 
estimate blow-off in swirling flames. Recently, Allison et al. [15] evaluated the LBO limits with complex fuels such as kerosene spray flames. They found that kerosene flames are less stable than simpler fuels. They used a 1/Da scaling equation (see Eq. 1] and found that laminar flame speed plays a dominant role in scaling. Further, they reported that this correlation could be used as a good approximation for spray flames. The kerosenes used in that work were standardised fuels coded as "A2", which is Jet-A and "C1", which is an alternative Gevo ATJ kerosene, described in Ref. [16]. On comparing kerosene fuels, the kerosene flames with a high derived cetane number (DCN) are more stable than those with a low DCN [15, 17, 18]. The spray characteristics near blow-off of alternative fuels were compared to A2 in Ref. [19]. Rock et al. [17] showed through $\mathrm{CH}^{*}$ images that the flames produced with high DCN have more re-ignition events, which makes them resilient to blow-off. This enhanced re-ignition behaviour of kerosene flames prolongs the blow-off duration. An increase in blow-off duration in kerosene flames was also observed in Ref. [13]. In that study, it was found that the blow-off duration of kerosene flames is 2.5 times longer than that in methane flames. This result was suggested to stem from pronounced low-temperature chemistry, which facilitates continuous re-ignition of the flame [13].

While these prior studies have provided significant insight into the LBO limits and structure of gaseous fuels, recent studies reported that flames with heavy hydrocarbon or complex fuels show a substantial difference in terms of LBO and flame structure [13, 15, 17]. Tambold et al. [20] showed that alcohol flames blow-off at higher equivalence ratios than methane. Carbone et al. [21] observed changes in global properties of the flame with complex fuels and suggested re-examining their scaling parameters. Additionally, it was observed in Refs. [20, 21] that flames with a high Lewis number $(L e)$ are more susceptible to extinction than those with a low $L e$.

It is clear that from a fundamental viewpoint LBO of turbulent premixed flames has focused on simple gaseous fuels and LBO scales with the square of the laminar flame speed in gaseous fuels. In addition, previous works concerning the LBO of kerosene-fueled flames has focused on spray flames, where it may be difficult to isolate fuel chemistry effects from those associated with the atomization and evaporation of different fuels. In this paper, the effect of fuel composition and Le on the LBO is studied with prevapourised ethanol, heptane, and two kerosenes (A2 and C1). The objectives of the current study are: (i) to measure the LBO limits of flames with various vapourised liquid fuels and evaluate the scaling parameters based on laminar flame speed; and (ii) to provide comparisons between the structural features of such flames via high-speed $\mathrm{OH}^{*}$ chemiluminescence imaging.

\section{Experimental setup}

Figure 1 a shows a schematic of the bluff body burner used in this work. A similar burner was employed in Refs. [9, 10, 13, 22, 23] to study the behaviour of methane flames. The burner consists of a conical bluff body mounted at the centre of a tube via a small rod with a diameter of $\sim 6.5 \mathrm{~mm}$. The bluff body possessed a $45^{\circ}$ half-angle, and its widest diameter, which aligned with the exit of the tube, measured $23 \mathrm{~mm}$. The tube had an inner diameter of $35 \mathrm{~mm}$, producing a $43 \%$ blockage ratio, was $300 \mathrm{~mm}$ long, and was mounted to a small plenum. To ensure smooth 
flow separation at the exit of the tube, its edge was tapered and filed to a sharp point. Additionally, a small section of honeycomb was fitted within the centre of the tube to facilitate flow straightening.

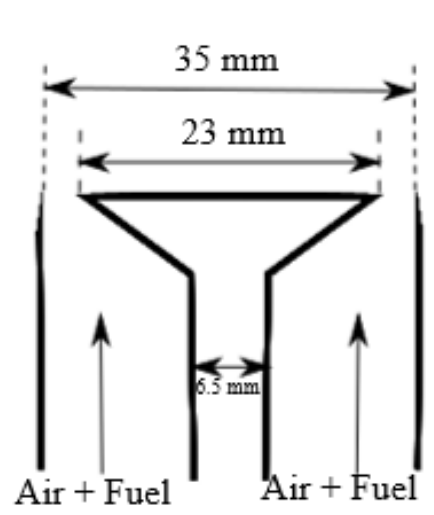

(a) Burner

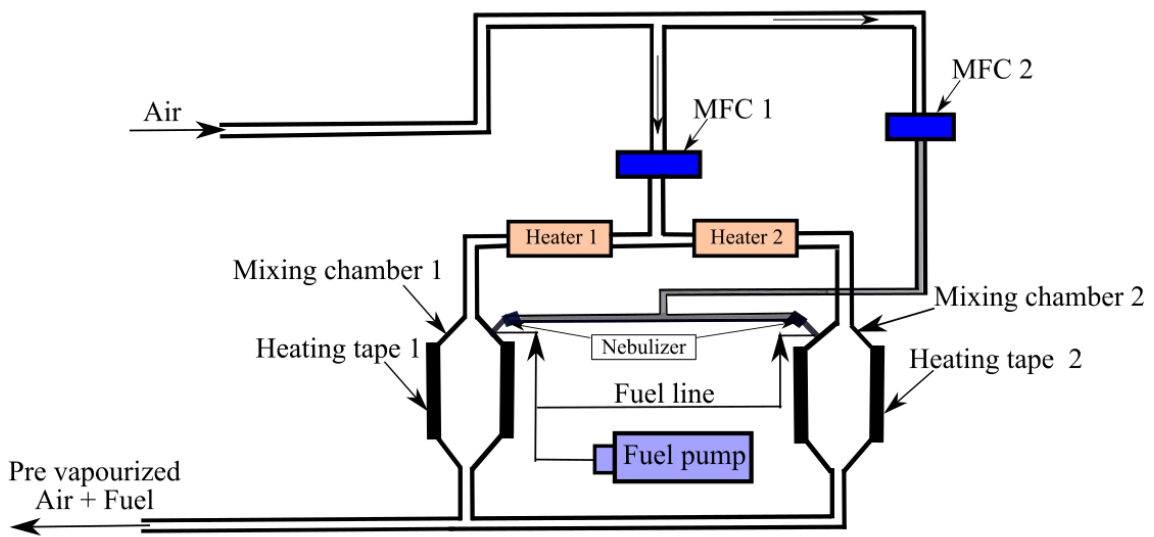

(b) Vaporiser

Fig. 1 Schematic of bluff body burner with bluff body diameter of $23 \mathrm{~mm}$ (left) and the vaporiser showing the critical parts (right).

The liquid fuel was vapourised before entering the burner. Figure $1 \mathrm{~b}$ shows a schematic of the vapouriser, which is a scaled-up version of the one employed in Ref. [21]. The vapouriser is designed to provide a maximum airflow rate of 1000 standard litres per minute at a temperature of $413 \mathrm{~K}$. The inlet air is heated using four inline air heaters, and the power of the heaters was controlled via a proportional-integral-derivative (PID) controller. The heated air is passed through two separate mixing chambers where the fuel is injected through nebulisers (Meinhard, TR-30-A10). The function of the nebulisers is to atomise the fuel, facilitating efficient evaporation. The mixing chambers are wrapped in heating tape to minimise heat loss to the walls. To ensure the mixture exiting the burner was fully vapourised, a series of Mie scattering and Phase Doppler Anemometry (PDA) measurements were made prior to the primary experimental campaign. Results from these measurements indicate that the vapouriser system vapourises $99.9 \%$ of the fuel. The temperature of the mixture was measured with a K-type thermocouple at the exit of the vapouriser and the burner. The temperature of the mixture was kept at $393 \pm 5 \mathrm{~K}$, which is above the saturation temperature of the fuels considered here. To reduce heat losses, the delivery pipes of the system were insulated with glass wool.

Bronkhorst mass flow controllers (accurate to within 3\% of the total flow rate) were used to control the air and fuel flow rates. Figure $1 \mathrm{~b}$ shows the primary and secondary flow controllers (MFC1 and MFC2, respectively). MFC 1 is used to regulate the airflow through the heaters, and the mixing chamber, whilst MFC 2 provides a small amount of air to the nebulizer to facilitate fine atomization of the liquid fuel. The liquid fuel was supplied to the nebulizers through silicon hosing (to prevent corrosion), and its flow rate was metered via a Bronkhorst gear pump and Coriolis flowmeter system.

The four liquid fuels studied were: ethanol, n-heptane (referred to as heptane), and two kerosene fuels. The two kerosene fuels considered were a conventional Jet-A blend, referred to as A2, and an alternative Gevo alcohol-to-jet 
(ATJ) kerosene, referred to as C1. These denominations follow the USA National Jet Fuel Combustion Program, where these fuels were procured [16]. The chemical composition and other key features of these kerosene fuels are provided in Ref. [16]. The primary difference between the two kerosenes was the derived cetane number (DCN); namely, A2 possesses a DCN of 48.8 while the $\mathrm{DCN}$ for $\mathrm{C} 1$ is 17.1 [16]. Ethanol and heptane were considered as they consist of a single component. Additionally, ethanol contains one hydroxyl group, and it will be interesting to see where alcohol lies on the blow-off curve in comparison to methane.

Two conditions were investigated: stable burning $\phi=0.75$ and close to blow-off $\phi / \phi_{b o}=1.01$, where $\phi$ is the equivalence ratio and $\phi_{b o}$ the equivalence ratio at LBO. The stable burning condition was chosen to have $\phi=0.75$ so that the results would be consistent with those presented in Ref. [9]. The bulk velocity $U_{b}$ at the annular opening was 23 $\mathrm{m} / \mathrm{s}$ for all cases considered. A summary of the experimental conditions is given in Table 1

Table 1 Summary of experimental conditions at temperature $393 \mathrm{~K}$ and velocity $23.5 \pm 1 \mathrm{~m} / \mathrm{s}$.

\begin{tabular}{|c|c|c|c|c|c|c|}
\hline \multirow[b]{2}{*}{ Fuel } & \multirow[b]{2}{*}{ Mechanism } & \multicolumn{3}{|c|}{ Far from blow-off } & \multicolumn{2}{|c|}{ Close to blow-off } \\
\hline & & Le & $\phi$ & $\begin{array}{c}\mathrm{S}_{L} \\
(\mathrm{~cm} / \mathrm{s})\end{array}$ & $\phi_{b o}$ & $\begin{array}{l}\mathrm{S}_{L, B O} \\
(\mathrm{~cm} / \mathrm{s})\end{array}$ \\
\hline Methane & USC Mech II [24] & 0.98 & 0.75 & 39.37 & 0.61 & 23.28 \\
\hline Ethanol & Marinov [25] & 1.68 & 0.75 & 44.97 & 0.641 & 31.70 \\
\hline Heptane & Smallbone et al. [26] & 2.8 & 0.75 & 43.50 & 0.635 & 30.43 \\
\hline A2 & HyChem (POSF10325) [27] & 4.6 & 0.75 & 40.09 & 0.68 & 33.07 \\
\hline $\mathrm{C} 1$ & HyChem (POSF11498) [28] & 5.0 & 0.75 & 36.91 & 0.71 & 33.43 \\
\hline
\end{tabular}

\section{Experimental Procedures and Diagnostics}

The following section first presents the method used to determine the LBO limits and the details of diagnostics techniques used in this work.

\section{A. Stability limits}

In the current study, the LBO limit was defined as the lowest equivalence ratio at which the flame remains visible for a given bulk velocity. The LBO limit was measured for a range of bulk velocities. The LBO limit was determined first by igniting a stable fuel-air mixture (i.e. one at an equivalence ratio of 0.9 ) and then subsequently reduce $\phi$ in steps of $1.5 \%$ every 20 seconds until the flame was no longer visible. The effect of reducing the fuel flow rate influences the bulk velocity by no more than $3 \%$, which is within the uncertainty of flow controllers. The procedure was repeated five times 
for each fuel and flow-rate combination. The standard deviation lies within the uncertainty of the instruments.

The LBO curves from different fuels were evaluated using Eq. 1. The term $\left(\frac{C_{1}}{C_{2}} \frac{15}{A}\right)$ in Eq. 1 is considered to be a constant of order 1, thus Eq. 1 can be rewritten as

$$
U_{B O}=D a_{B O}^{-2}\left(\frac{S_{L, B O}^{2} d}{v}\right)
$$

where $v$ was evaluated at a pressure of $1 \mathrm{~atm}$ and the temperature of the air utilized for each condition. The laminar flame speed $\left(S_{L, B O}\right)$ was also computed by considering these mixture temperatures and the specific equivalence ratio at LBO. The mechanism used for each fuel and the corresponding $S_{L, B O}$ is given in Table 1 .

\section{B. $\mathrm{OH}^{*}$ chemiluminescence system}

For $\mathrm{OH}^{*}$ chemiluminescence measurements, a monochrome CMOS high-speed camera (Photron SA1.1) equipped with a two-stage high-speed intensifier (LaVision IRO) with a spectral range of 190 to $800 \mathrm{~nm}$ was used. Attached to the IRO was a UV 100-mm f/2.8 lens (Cerco), which was fitted with a band-pass filter (270-370 mm). The intensifier was gated to $130 \mu \mathrm{s}$ and the images were obtained at a rate of $5.4 \mathrm{kHz}$. The sensor of the camera possesses $1024 \times 1024$ pixel $^{2}$, which imaged a field of view (FOV) that was 90 (tall) $\times 90$ (wide) $\mathrm{mm}^{2}$, resulting in a projected pixel size of $\sim 88 \mu \mathrm{m}$. The $\mathrm{OH}^{*}$ images were cropped to obtain the region of interest, which was 36 (tall) $\times 40$ (wide) $\mathrm{mm}^{2}$. The measurements were performed with the aforementioned liquid fuels (see Table 1).

\section{Result and Discussion}

In this section LBO limits and flame shapes in the form of instantaneous and average $\mathrm{OH}^{*}$ chemiluminescence images are presented and discussed.

\section{A. Lean blow-off limits with different fuels}

Figure 2 shows the LBO curve for the kerosene (A2 and C1) and single-component fuels (methane, ethanol, and heptane). As observed in prior studies (e.g., Refs. [9, 15, 22]), the equivalence ratio at which the flames blow-off increases with higher $U_{b}$. Figure 2 indicates that the kerosene fuels are less stable than ethanol and heptane, with $\mathrm{C} 1$ flames being the least stable. As Fig. 2 shows, methane flames are found to be the most resilient, while the stability curves for ethanol and heptane fall between those for the methane- and the kerosene flames. Additionally, for the two kerosene flames, it was observed that the one with a higher DCN (A2 in this case) was more stable, which is consistent with the findings in Ref. [17].

For each of the LBO points, the corresponding laminar flame speed was estimated and the LBO limits were evaluated with the correlation of Radhakrishnan et al. [8] derived in the context of turbulent premixed flames given in Eq.2. Also, the correlation is applied to the methane flame LBO data measured by Kariuki et al. [9, 22]. Figure 3a shows these 


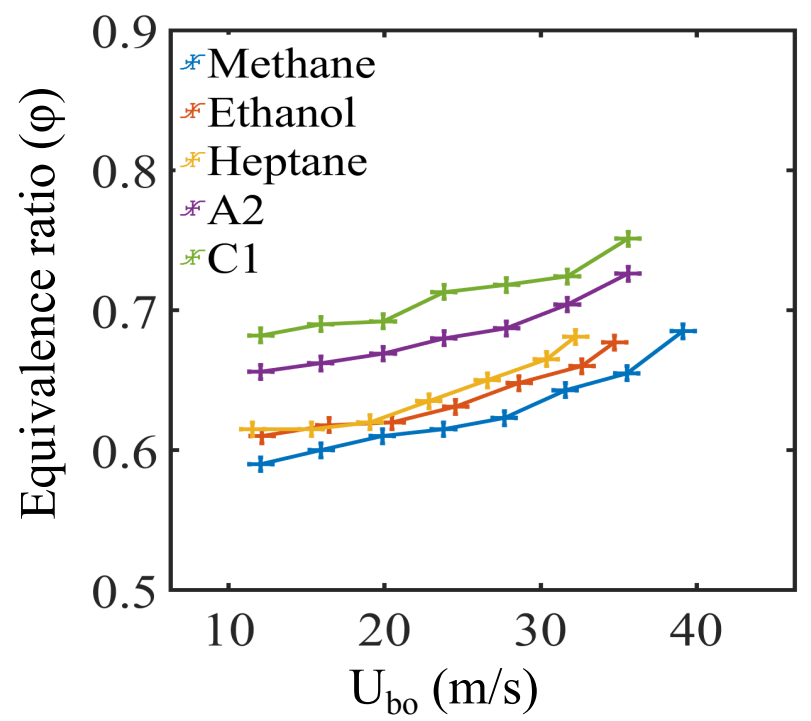

Fig. 2 Plots showing the LBO Limits $\left(\phi_{b o}\right)$ as a function of $\mathrm{LBO}$ velocity $\left(U_{b o}\right)$.The error bars represents the uncertainty in experiments in velocity and equivalence ratio.

results. The slope of the curve in Fig. 3 is represented by $D a_{B O}^{-2}$. The intercepts in Fig. 3 point out that they are non-physical merely because of the correlation in Eq. 2] does not apply to flames in laminar limits. The value of $1 / D a$ varies between 0.82 and 0.88 for methane flames at the blow-off velocities considered here. In the case of vaporised liquid fuels, this variation is from 0.38 to 0.52 . The variation in the $1 / D a$ values is not significant. Shanbhogue et al. [6] and Kariuki [22] reported a similar variation of $1 / D a$, where this scaling was found to hold for methane flames. The solid black lines in Fig. 3 represent these $D a$ values. It was observed that $D a_{B O}^{-2}$ values collapse reasonably well for the separate liquid fuels and is $\approx 0.48$ over the range of bulk velocities considered here. In contrast, the methane flames are found to have $D a_{B O}^{-2}$ values of $\approx 0.97$, which is consistent with the results of Kariuki et al. [22].

Since the vapourised liquid hydrocarbon fueled flames were operated at an elevated temperature (to ensure complete vaporisation), a series of stability tests were performed with methane at both ambient and elevated temperatures (298 K and $393 \mathrm{~K}$, respectively) and the $S_{L}$ was computed at the respective temperature. These results are also presented in Fig. 3a, which shows that an increased reactant temperature has little to no effect on the stability of the methane flames. Thus, the difference in stability between methane and the other fuels is not a consequence of the latter being preheated before combustion.

Shanbhogue et al. [6] and Radhakrishnan et al. [8] showed that for a particular bluff-body type (2-D vs axisymmetric), the LBO limits collapse around a single value of $D a$ regardless of the gaseous fuel used. Since the methane and liquid fuel flames considered here do not collapse to a single value of $D a$, this correlation is not sufficient for predicting the LBO limit of heavier hydrocarbon fuels. Within this $D a$-based scaling correlation, aspects of the combustion chemistry are subsumed into one parameter: $S_{L}$. Yet, the inability of this correlation to yield a proper collapse of the data suggests that $S_{L}$ does not adequately capture the relevant combustion phenomena when complex hydrocarbon fuels 


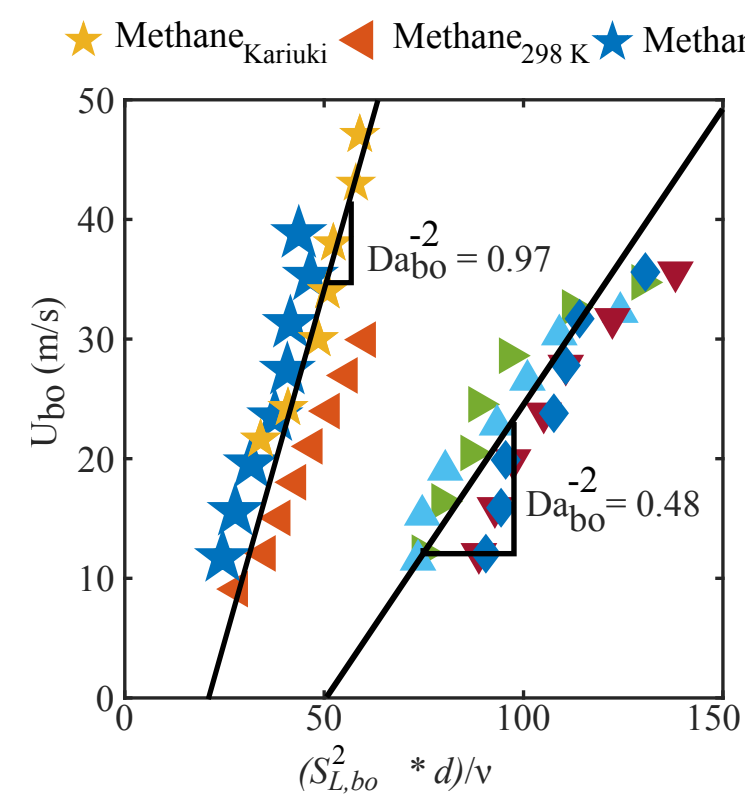

(a) Value of $\mathrm{Da}_{\text {bo }}^{-2}$ based on correlation of Radhakrishnan et al. [5].

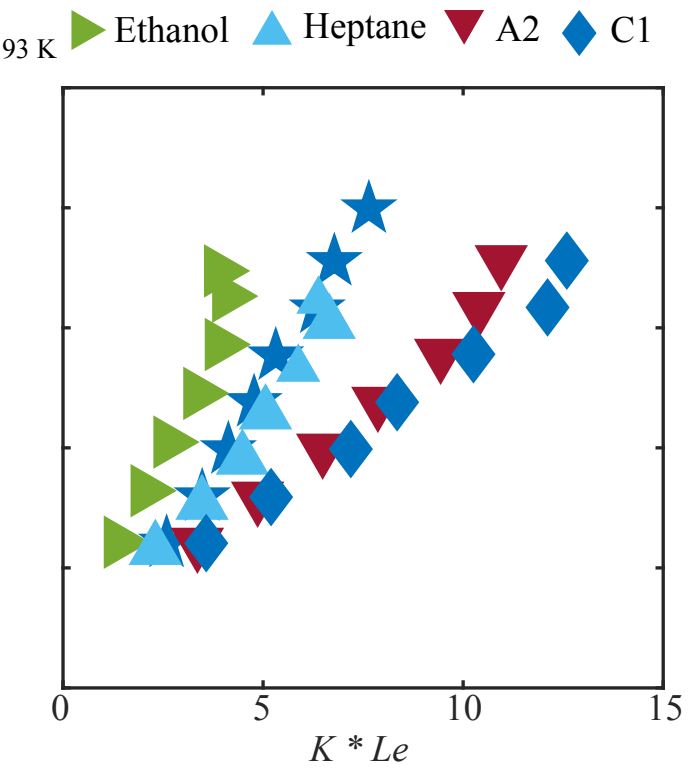

(b) Value of $K *$ Le based on Abdel-Gayed and Bradley's correlation [83, 84].

Fig. 3 Plots showing the $D a_{B O}^{-2}$ and $K \times L e$ as a function of blow-off velocity $\left(U_{B O}\right)$ for single-component and multi-component fuels.

are considered. Notably, this is supported by the fact that A2 and methane flames tend to have similar values of $S_{L}$ (see Table 11, yet such flames possess drastically different LBO limits. Furthermore, the failure of simple $S_{L}$-based scaling laws to track observed results for complex hydrocarbon fueled flames was also reported in Ref. [21]. Hence, parameters beyond $S_{L}$ are likely necessary to fully encapsulate the combustion chemistry associated with complex hydrocarbon fueled flames.

Previous studies emphasized the role of extinction and $L e$ in governing LBO [11, 21, 29]. Abdel-Gayed and Bradley [30] proposed a correlation based on the turbulent Karlovitz stretch factor $(K)$ and $L e$. They reported that the flame quenches if $K \times L e>1.5$. Here, $K$ was estimated at LBO based on the assumptions used in Ref. [31]. They assumed that the average turbulent intensity is $u^{\prime} / U_{b o}=0.2$ ( $u^{\prime}$ is the rms of the velocity fluctuations), and that turbulent length scale $(L)$ can be approximated by $d / 5$. With this crude analysis, $K$ is defined as $K=\delta u^{\prime}\left(S_{L} \lambda_{T}\right)^{-1}$ and can be rewritten as $0.125\left(u^{\prime} / S_{L}\right)^{2}\left(R e_{t}\right)^{-1 / 2}$ [32], where $R e_{t}$ is the turbulent Reynolds number and $\delta$ is the laminar flame thickness. The variation in $R e_{t}$ is from 430 to 1450 for different velocity conditions. Based on these assumptions $K$ lies in the range of 1.08 - 2.30 for the different flames studied here, while their $L e$ span from 0.98 to 5.0 (see Table 1). Figure 3 b shows the value of $K \times L e$ at the LBO velocity for all five fuels. The estimated $K$ numbers in the current study are higher than those ascribed to the limit above which spherically expanding turbulent premixed flames cannot be sustained [30, 32]. Thus, based on Abdel-Gayed and Bradley's correlation, the extinction $K$ for methane is $\approx 1.5$ while that for A2 is $\approx 0.32$. This implies that heavier hydrocarbon fueled flames are more susceptible to extinction than methane, which 
may explain why kerosene flames blow-off at higher equivalence ratios than those produced with methane. Namely, the above analysis based on Abdel-Gayed and Bradley's results suggests that the $L e$ of the fuel influences its propensity for extinction. In past studies, which primarily considered simple gaseous fuels, Le effects were negligible because the fuels had $L e \approx 1$. Moreover, Law [33] showed that flames with $L e>1$ (e.g., heptane, A2, and C1) could experience extinction solely because of sufficient straining; however, flames with $L e \leq 1$ require incomplete combustion, heat loss, or high rates of curvature for extinction to occur. It is apparent from Fig. 2 and Table 1 that the LBO equivalence ratio increases with $L e$. Therefore, it can be assumed that vaporized liquid fuels with $L e>1$ experience a higher degree of localized extinction, which causes these flames to blow-off at higher equivalence ratios than methane flames.

Twin counterflow strained laminar premixed flame simulations were performed to obtain the laminar extinction strain rates, $S_{\text {lam }}$, at the blow-off equivalence ratio for all five fuels. Shanbhogue et al. [6] suggested that the chemical time scale based on extinction strain rate may provide better grouping of the data. Thus, the extinction strain rate was estimated at the blow-off equivalence ratio at each velocity condition for all fuels considered in the current study. Figure 4 shows the laminar extinction strain rate from the simulation as a function of the bulk velocity. Methane exhibits the highest value of extinction strain rate. Heptane and the two kerosenes (A2 and C1) possess nearly the same extinction strain rate and ethanol has an extinction strain rate between those of methane and heptane and the kerosenes. The data in Fig. 4 demonstrate that the separate fuels considered here result in different values of $\left(d / U_{b o}\right) / S_{l a m}$, and hence the laminar flame extinction strain rate does not collapse well the blow-off condition of different fuels.

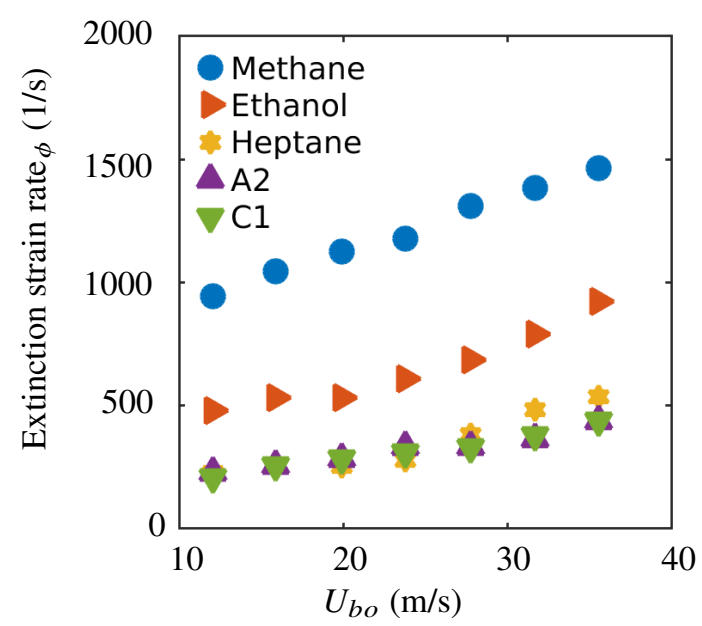

Fig. 4 Variation of simulated extinction strain rate from the twin flame simulation as the function of equivalence ratio with $U_{b o}$.

The analysis above attempts to correlate the onset of blow-off with terms like $S_{L}, K \times L e$, or $S_{\text {lam }}$; however, such efforts have failed to fully collapse the LBO data across the range of fuels studied here. This implies that the extrapolation of knowledge from flames of small hydrocarbons (e.g. methane, ethylene) to higher hydrocarbons (e.g. heptane, kerosenes) cannot simply be based on concepts where all the combustion chemistry is expressed through $S_{L}$, 
even after considering $L e$ or strain effects.

\section{B. Flame Shape}

High-speed $\mathrm{OH}^{*}$ chemiluminescence was used to characterize the flame shape. $\mathrm{OH}^{*}$ can be used to roughly indicate the location of key chemical reactions within premixed flames [34, 35]. The average flame shape was obtained by averaging 5400 instantaneous $\mathrm{OH}^{*}$ chemiluminescence images. Figures 5 and 6 show the instantaneous and average images with ethanol, heptane, A2, and C1 from conditions far from and close to blow-off, respectively.
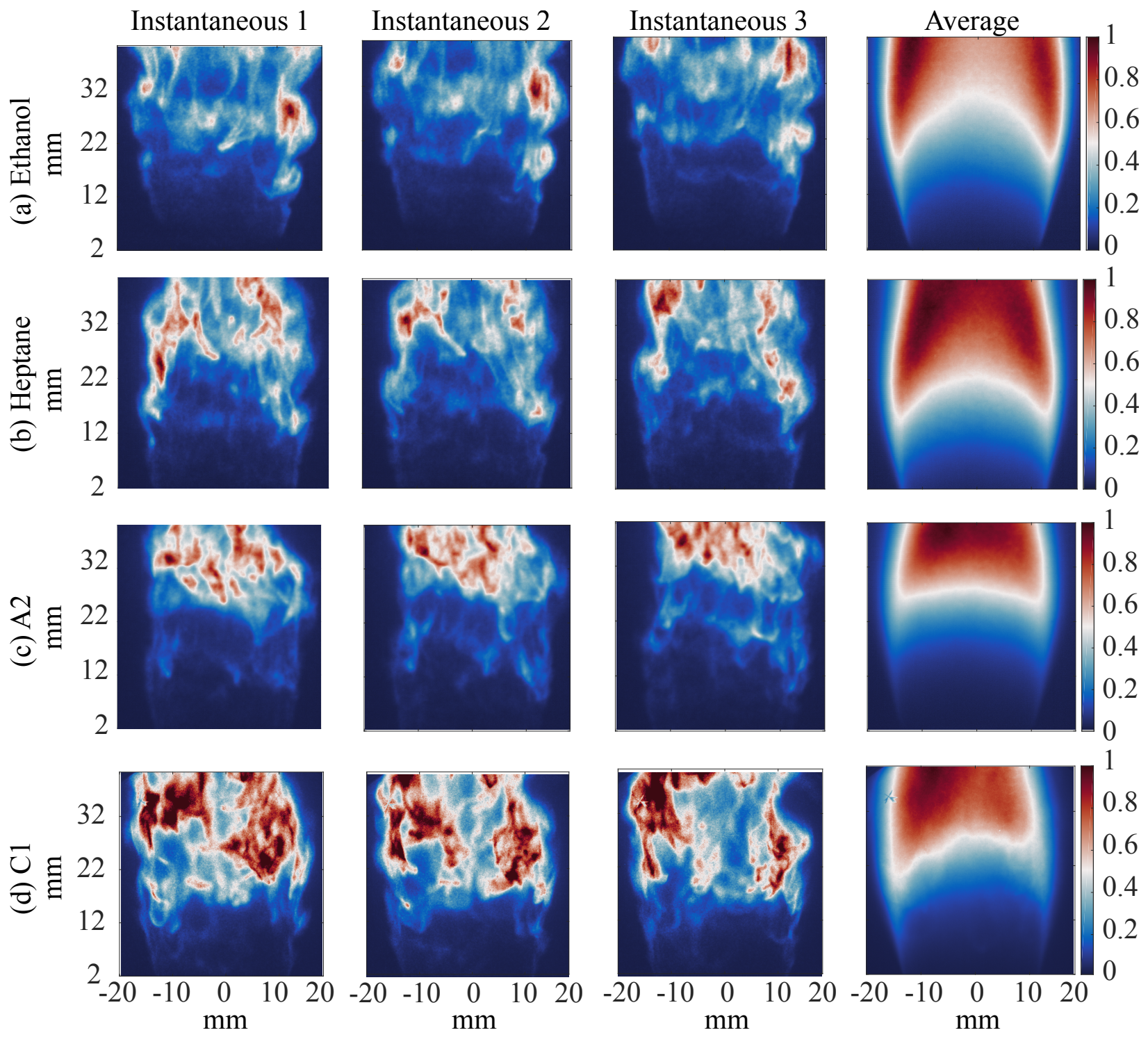

Fig. $5 \mathrm{OH}^{*}$ chemiluminescence images at far from blow-off. The centre line of the bluff body is represented by the ' 0 ' in radial axis.

The instantaneous images from conditions far from blow-off exhibit high intensity $\mathrm{OH}^{*}$ chemiluminescence signal along the shear layer. The high intensity island of $\mathrm{OH}^{*}$ were observed in the instantaneous images with all four flames. 
These localized high-intensity islands of $\mathrm{OH}^{*}$ were more pronounced in the kerosene and heptane flames. Such localized increase in $\mathrm{OH}^{*}$ signal may be associated with the continuous re-ignition of the flame in RZ as observed by Ref. [17]. The average images shown in the rightmost column of Fig. 5 highlight the features of the instantaneous images. Overall, when far from blow-off, all four flames display similar structure with low intensity $\mathrm{OH}^{*}$ signal close to the bluff body and high intensities in the downstream regions.
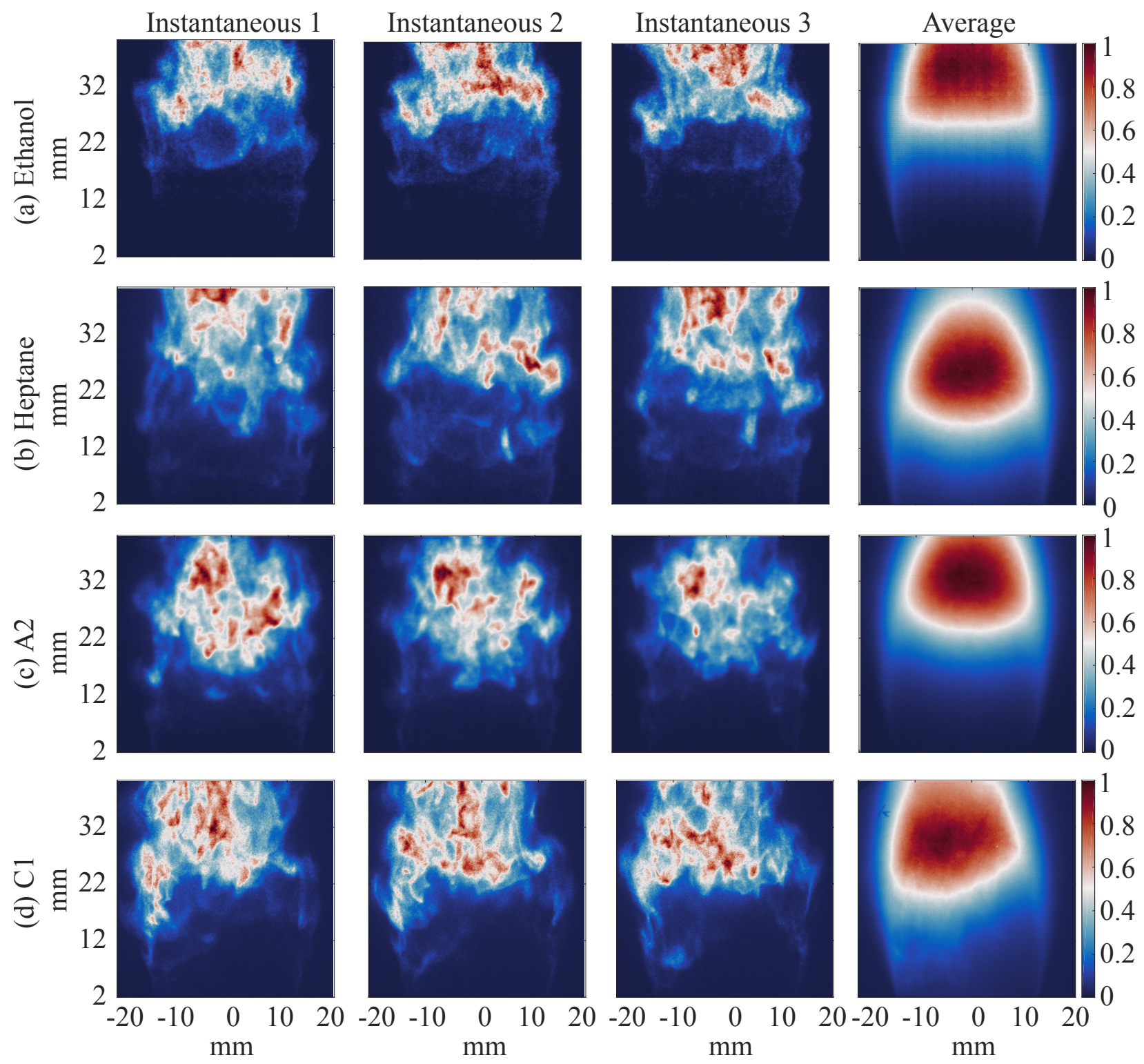

Fig. $6 \mathrm{OH}^{*}$ chemiluminescence images at close to blow-off. The centre line of the bluff body is represented by the ' 0 ' in radial axis.

Figure 6 shows similar information as Fig. 5 but from conditions close to LBO. It is evident from Fig. 6 that all four flames become shorter as $\phi$ was reduced. The highest intensity of the $\mathrm{OH}^{*}$ signal was observed to exist in regions 30-40 mm downstream of the bluff body in the RZ. During blow-off, the methane flames were found to exhibit a similar 
shortening and confinement within the RZ as in Ref. [9]. From the velocity field measurements presented in Ref. [9], the height of the RZ was determined to be 1.5 - 2 times the bluff-body diameter. Since the burner employed here is similar to that in Refs. [9], the RZ is estimated to extend $46 \mathrm{~mm}$ downstream of the bluff body. Thus, similar to the methane flames [9], vapourised liquid fuels close to blow-off (Fig. 6) exhibit a large amount of reaction within the RZ. Also, these flames become narrow at their tip, implying that flame fronts from the opposite sides of the burner merge, leading to the closing of the closing of the RZ in the downstream region (see average images in Fig. 6). Similar behaviour was observed with methane-, propane-, and ethylene-fueled flames in Refs. [9-11, 31].

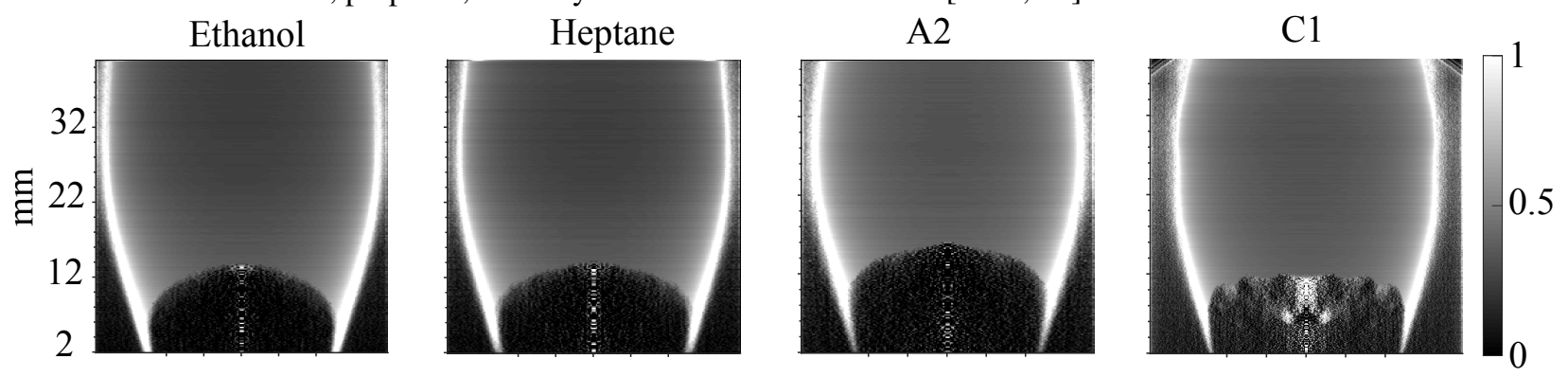

(a) Abel transformed images far from blow-off $(\varphi=0.75)$

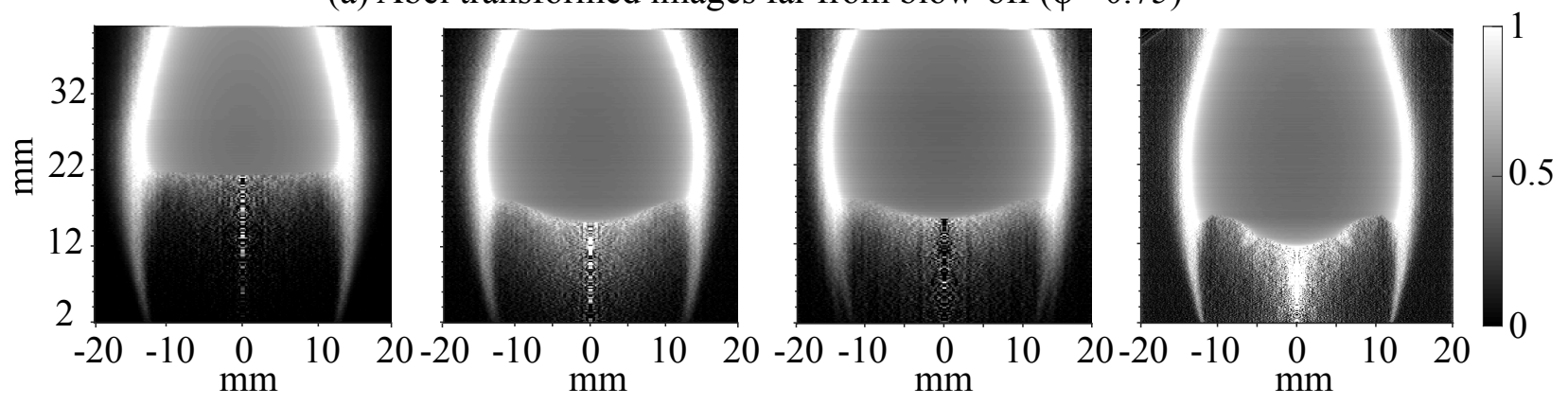

(b) Abel transformed images close to blow-off $\left(\varphi / \varphi_{b o}=1.01\right)$

Fig. 7 Abel transformed images with ethanol, heptane, A2 and C1.

The average $\mathrm{OH}^{*}$ images presented indicate that the flames are symmetric; thus, these images were Abel transformed to provide a projection of the mean reaction rate within a 2-D plane [31]. Figure $7 \mathrm{a}$ and $\mathrm{b}$ displays the Abel transformation of averaged $\mathrm{OH}^{*}$ chemiluminescence images for all flames at conditions far from and close to blow-off. When far from blow-off, the Abel transformed images appear similar for all four flames. The primary reactions are concentrated along the annular jet of the reactants. Low signal intensity inside the RZ can be related to the burnt gases. At conditions close to blow-off, reaction zones are observed inside the RZ. Additionally, in the downstream part of the flames the two flame brushes from both sides of the burner are observed to merger together. Moreover, flames operated with heptane and kerosene (A2 and C1) display average reaction regions closer to the bluff body than those fueled with ethanol. These findings are consistent with those presented in Ref. [9, 31], where average reaction regions were observed within the RZ of methane flames. 


\section{Conclusions}

The effect of fuel properties on the blow-off limits and flame shape were investigated for vapourised ethanol, heptane, and two separate kerosene fuels (A2 and C1) in a bluff-body burner. The kerosene fuels comprised of a conventional Jet-A blend (A2) and an alternative Gevo ATJ kerosene (C1). It was observed that the methane, ethanol and heptane flames are more resilient to blow-off than the kerosene flames (i.e., A2 and C1). Also, the stability limits were evaluated using a correlation based on a characteristic Damköhler number $(D a)$. The correlation was not successful in collapsing the stability points associated with the liquid-fueled flames to the line derived for methane flames. This suggests that correlations wherein the combustion chemistry is solely subsumed within the laminar flame speed (i.e. that based on a characteristic $D a$ ) is not likely to be universally applicable. $\mathrm{OH}^{*}$ images showed that all four liquid fuels exhibit a similar flame shape at stable burning conditions. Close to blow-off, the flames become shorter with reaction zones lying inside the RZ. Moreover, the flame fronts from either side of burner bent towards the axis and merged in the downstream region of the RZ.

\section{Acknowledgments}

The authors would like to thank Drs. Tim Edwards and Med Colket for assistance with the standardized kerosene fuels used in this study. The authors also want to thank Mr. Roberto Ciardiello for helping with the experiments. Additionally, the authors are grateful for Drs. Patton Allison and Pedro de Oliveira's support in developing and building the vaporizer system employed in this study. We are grateful to Prof. F. Egolfopoulos for sharing their design. Rohit S. Pathania is grateful for the financial support of Cambridge Trust and SERB India.

\section{References}

[1] Cheng, R., and Levinsky, H., "6 - Lean Premixed Burners," Lean Combustion (Second Edition), edited by D. Dunn-Rankin and P. Therkelsen, Academic Press, Boston, 2016, second edition ed., pp. 203 - 229. https://doi.org/https://doi.org/10.1016/B978-012-804557-2.00006-7

[2] Liu, Y., Sun, X., Sethi, V., Nalianda, D., Li, Y.-G., and Wang, L., "Review of Modern Low Emissions Combustion Technologies for Aero Aas Turbine Engines,” Progress in Aerospace Sciences, Vol. 94, 2017, pp. 12 - 45. https://doi.org/https: //doi.org/10.1016/j.paerosci.2017.08.001

[3] Correa, S. M., "A Review of NOx Formation Under Gas-Turbine Combustion Conditions," Combustion Science and Technology, Vol. 87, No. 1-6, 1993, pp. 329-362. https://doi.org/10.1080/00102209208947221

[4] Echekki, T., and Mastorakos, E., “Turbulent Combustion Modeling: Advances, New Trends and Perspectives," Fluid Mechanics and Its Applications, Springer Netherlands, 2010. https://doi.org/10.1007/978-94-007-0412-1

[5] Law, C. K., Combustion Physics, Cambridge University Press, 2006. https://doi.org/10.1017/CBO9780511754517. 
[6] Shanbhogue, S. J., Husain, S., and Lieuwen, T., "Lean Blowoff of Bluff Body Stabilized Flames: Scaling and Dynamics," Progress in Energy and Combustion Science, Vol. 35, No. 1, 2009, pp. 98-120. https://doi.org/10.1016/j.pecs.2008.07.003

[7] Longwell, J. P., Frost, E. E., and Weiss, M. A., "Flame Stability in Bluff Body Recirculation Zones," Industrial Engineering Chemistry, Vol. 45, No. 8, 1953, pp. 1629-1633. https://doi.org/10.1021/ie50524a019

[8] Radhakrishnan, K., Heywood, J. B., and Tabaczynski, R. J., "Premixed Turbulent Flame Blowoff Velocity Correlation Based on Coherent Structures in Turbulent Flows," Combustion and Flame, Vol. 42, No. C, 1981, pp. 19-33. https://doi.org/10.1016/00102180(81)90139-5

[9] Kariuki, J., Dawson, J. R., and Mastorakos, E., "Measurements in Turbulent Premixed Bluff Body Flames Close to Blow-off," Combustion and Flame, Vol. 159, No. 8, 2012, pp. 2589-2607. https://doi.org/10.1016/j.combustflame.2012.01.005

[10] Kariuki, J., Dowlut, A., Balachandran, R., and Mastorakos, E., "Heat Release Imaging in Turbulent Premixed Ethylene-Air Flames Near Blow-off," Flow, Turbulence and Combustion., Vol. 96, No. 4, 2016, pp. 1039-1051. https://doi.org/10.1007/s10494-0169720-y

[11] Chaudhuri, S., Kostka, S., Renfro, M. W., and Cetegen, B. M., "Blowoff Dynamics of Bluff Body Stabilized Turbulent Premixed Flames," Combustion and Flame, Vol. 157, No. 4, 2010, pp. 790 - 802. https://doi.org/https://doi.org/10.1016/j.combustflame. 2009.10 .020

[12] Chaudhuri, S., and Cetegen, B. M., "Blowoff Characteristics of Bluff-body Stabilized Conical Premixed Flames with Upstream Spatial Mixture Gradients and Velocity Oscillations," Combustion and Flame, Vol. 153, No. 4, 2008 , pp. 616 - 633. https://doi.org/https://doi.org/10.1016/j.combustflame.2007.12.008.

[13] Pathania, R., Skiba, A., Ciardiello, R., and Mastorakos, E., "Blow-off Mechanisms of Turbulent Premixed Bluff-body Stabilised Flames Operated with Vapourised Kerosene Fuels (accepted),” Proceedings of the Combustion Institute, 2020.

[14] Cavaliere, D. E., Kariuki, J., and Mastorakos, E., "A Comparison of the Blow-off Behaviour of Swirl-Stabilized Premixed, Non-premixed and Spray Flames," Flow, Turbulence and Combustion., Vol. 91, No. 2, 2013, pp. 347-372. https://doi.org/10. 1007/s10494-013-9470-z.

[15] Allison, P. M., Sidey, J. A., and Mastorakos, E., "Lean Blowoff Scaling of Swirling, Bluff-Body Stabilized Spray Flames,” AIAA Aerospace Sciences Meeting, paper no. 1421, 2018. https://doi.org/10.2514/6.2018-1421

[16] Colket, M., Heyne, J., Rumizen, M., Gupta, M., Edwards, T., Roquemore, W. M., Andac, G., Boehm, R., Lovett, J., Williams, R., Condevaux, J., Turner, D., Rizk, N., Tishkoff, J., Li, C., Moder, J., Friend, D., and Sankaran, V., "Overview of the National Jet Fuels Combustion Program,” AIAA Journal, Vol. 55, No. 4, 2017, pp. 1087 - 1104. https://doi.org/https: //doi.org/10.2514/1.J055361

[17] Rock, N., Emerson, B., Seitzman, J., and Lieuwen, T., "Near Lean Blowoff Dynamics in a Liquid Fueled Combustor," Combustion and Flame, Vol. 212, 2020, pp. 53 - 66. https://doi.org/https://doi.org/10.1016/j.combustflame.2019.10.010. 
[18] Stouffer, S., Hendershott, T., Monfort, J. R., Diemer, J., Corporan, E., Wrzesinski, P., and Caswell, A. W., "Lean Blowout and Ignition Characteristics of Conventional and Surrogate Fuels Measured in a Swirl Stabilized Combustor," 55th AIAA Aerospace Sciences Meeting, paper no. 1954, 2017. https://doi.org/10.2514/6.2017-1954

[19] Shin, D., Bokhart, A. J., Rodrigues, N. S., Sojka, P. E., Gore, J. P., and Lucht, R. P., "Nonreacting Spray Characteristics for Alternative Aviation Fuels at Near-Lean Blowout Conditions," Journal of Propulsion and Power, Vol. 36, No. 3, 2020 , pp. 323-334. https://doi.org/10.2514/1.B37712

[20] Trabold, J., Hartl, S., Walther, S., Johchi, A., Dreizler, A., and Geyer, D., "Fuel Effects in Turbulent Premixed Pre-vaporised Alcohol/Air Jet Flames," Flow, Turbulence and Combustion, 2020. https://doi.org/10.1007/s10494-020-00166-6, URL https://doi.org/10.1007/s10494-020-00166-6

[21] Carbone, F., Smolke, J. L., Fincham, A. M., and Egolfopoulos, F. N., "Comparative Behavior of Piloted Turbulent Premixed Jet Flames of C1-C8 Hydrocarbons," Combustion and Flame, Vol. 180, 2017, pp. 88 - 101. https://doi.org/https://doi.org/10.1016/ j.combustflame.2017.02.030

[22] Kariuki, J., “Turbulent Premixed Flame Stabilization and Blow-off,” University of Cambridge, Ph.D. thesis., 2012.

[23] Kariuki, J., Dowlut, A., Yuan, R., Balachandran, R., and Mastorakos, E., "Heat Release Imaging in Turbulent Premixed Methane-air Flames Close to Blow-off," Proceedings of the Combustion Institute, Vol. 35, No. 2, 2015 , pp. 1443 - 1450. https://doi.org/https://doi.org/10.1016/j.proci.2014.05.144

[24] Wang, H., You, X., Joshi, A. V., Davis, S. G., Laskin, A., Egolfopoulos, F., and Law, C. K., "USC Mech Version II. High-Temperature Combustion Reaction Model of H2/CO/C1-C4 Compounds," May, 2007. URL http://ignis.usc.edu/USC_ Mech_II.htm.

[25] Marinov, N. M., “A Detailed Chemical Kinetic Model for High Temperature Ethanol Oxidation,” International Journal of Chemical Kinetics, Vol. 31, No. 3, 1999, pp. 183-220. https://doi.org/10.1002/(SICI)1097-4601(1999)31:3<183::AIDKIN3>3.0.CO;2-X

[26] Smallbone, A., Liu, W., Law, C., You, X., and Wang, H., "Experimental and Modeling Study of Laminar Flame Speed and Non-premixed Counterflow Ignition of n-heptane," Proceedings of the Combustion Institute, Vol. 32, No. 1, 2009, pp. 1245 1252. https://doi.org/https://doi.org/10.1016/j.proci.2008.06.213

[27] Wang, H., Xu, R., Wang, K., Bowman, C. T., Hanson, R. K., Davidson, D. F., Brezinsky, K., and Egolfopoulos, F. N., “A Physics-based Approach to Modeling Real-fuel Combustion Chemistry - I. Evidence from Experiments, and Thermodynamic, Chemical Kinetic and Statistical Considerations," Combustion and Flame, Vol. 193, 2018, pp. 502 - 519. https://doi.org/https: //doi.org/10.1016/j.combustflame.2018.03.019

[28] Wang, K., Xu, R., Parise, T., Shao, J., Movaghar, A., Lee, D. J., Park, J.-W., Gao, Y., Lu, T., Egolfopoulos, F. N., Davidson, D. F., Hanson, R. K., Bowman, C. T., and Wang, H., "A Physics-based Approach to Modeling Real-fuel Combustion Chemistry - IV. 
HyChem Modeling of Combustion Kinetics of a Bio-derived Jet Fuel and its Blends with a Conventional Jet A," Combustion and Flame, 2018. https://doi.org/https://doi.org/10.1016/j.combustflame.2018.07.012

[29] Aspden, A., Bell, J., Day, M., and Egolfopoulos, F., “Turbulence-flame Interactions in Lean Premixed Dodecane Flames," Proceedings of the Combustion Institute, Vol. 36, No. 2, 2017, pp. 2005 - 2016. https://doi.org/https://doi.org/10.1016/j.proci. 2016.07 .068

[30] Abdel-Gayed, R., and Bradley, D., "Criteria for Turbulent Propagation Limits of Premixed Flames," Combustion and Flame, Vol. 62, No. 1, 1985, pp. 61 - 68. https://doi.org/https://doi.org/10.1016/0010-2180(85)90093-8

[31] Dawson, J. R., Gordon, R. L., Kariuki, J., Mastorakos, E., Masri, A. R., and Juddoo, M., “Visualization of Blow-off Events in Bluff-body Stabilized Turbulent Premixed Flames,” Proceedings of the Combustion Institute, Vol. 33, No. 1, 2011, pp. 1559-1566. https://doi.org/10.1016/j.proci.2010.05.044

[32] Abdel-Gayed, R., Bradley, D., and Lung, F. K. K., "Combustion Regimes and the Straining of Turbulent Premixed Flames," Combustion and Flame, Vol. 76, No. 1, 1989, pp. 213 - 218. https://doi.org/https://doi.org/10.1016/0010-2180(85)90093-8

[33] Law, C., "Dynamics of Stretched Flames," Symposium (International) on Combustion, Vol. 22, No. 1, 1989 , pp. 1381 - 1402. https://doi.org/https://doi.org/10.1016/S0082-0784(89)80149-3.

[34] Najm, H. N., Knio, O. M., Paul, P. H., and Wyckoff, P., “A Study of Flame Observables in Premixed Methane - Air Flames," Combustion Science and Technology, Vol. 140, No. 1-6, 1998, pp. 369-403. https://doi.org/10.1080/00102209808915779

[35] Ayoola, B. O., Balachandran, R., Frank, J. H., Mastorakos, E., and Kaminski, C. F., "Spatially resolved heat release rate measurements in turbulent premixed flames," Combustion and Flame, Vol. 144, No. 1-2, 2006, pp. 1-16. https: //doi.org/10.1016/j.combustflame.2005.06.005 